\title{
Effectiveness Evaluation of Command and Control System in Joint Operations
}

\author{
Chen-yan Kong \\ Science and Technology on Information System \\ Engineering key Laboratory \\ Nanjing, China \\ e-mail: kdemao@sina.com
}

\author{
Wei Chen \\ The $28^{\text {th }}$ Research Institute of China Electronic Science \\ \& Technology Group Inc. \\ Nanjing, China \\ e-mail: chenwei@sohu.com
}

\begin{abstract}
The effectiveness evaluation indicators hierarchy of command and control system in joint operations is constructed based on the analysis of the architecture and characteristics. The main methods of effectiveness evaluation are discussed. According to characteristics of the joint operations, the design goal and the scheme are given by using combat-simulationbase method and the experiment framework of effectiveness evaluation for command and control system in the joint operations is designed and implemented.
\end{abstract}

Keywords- command and control system in joint operations; effectiveness evaluation; combat-simulation-based method

\section{INTRODUCTION}

Under the conditions of modern information technology, joint operations have become the main form of combat. Command and control system is the "brain" and "nerve center" of the joint operations which hinges all kinds of equipment, links everything together. Without it, commanders can't get the condition of the arms and troops, the entire system can't form a closed loop. The study of effectiveness evaluation on command and control system in the joint operations can provide a standard and basis for the construction of the system. We study the operational use of various components of the system, analyze the emergence behavior arising from the result of the interaction between the various constituent combat forces, and learn how to optimize operational effectiveness in the confrontation systems, which is a very important and also a complex problem.

\section{ANALYSIS OF EFFECTIVENESS EVALUATION INDICATORS}

\section{A. Characteristics of command and control system in the joint operations}

Command and Control system is a part of the whole system of the joint operations. It takes charge of making operational plans, keeping combat forces in harmony, and conducting the operations of all combat forces. Compared to the traditional command and control system, the new characteristics are listed as follows:

- Combat spatial perception

Joint operations system is a Network-centric system, fully integrated with space-based, land-based, seabased, air-based sensor information system. The "information structure” establishment greatly improves the ability of combat spatial perception, but also requires higher processing capacity of command and control system. The command and control system should be able to obtain, transmit and process combat information timely and effectively, fuse the data in both the physic and information space, integrate the intelligence information and the combat situation, get out of the crude and fake information and keep the fine and the real, integrate different level and different type of command and control systems, so that the commanders could have the consistent perception and understanding for the battlefield to ensure the effective command for the various operations of combat forces[1].

- Operational synergies

There are many branches of military forces and professional information combat forces participate in the joint operations, also include a wide range of equipment. The various operations interact and influence each other. It is difficult to play a good role for command and control system if Operational synergies failed, even affect its own normal operations of electronic equipment, and then affect the implementation of other combat operations. Therefore, command and control system in the joint operations must plan, correspond and control combat forces macroscopically, to make good organization and coordination for each combat operation to get mutual support and mutual enhancement, in order to obtain enhanced joint operational effectiveness.

- Combat effect

The final result of the above characteristics is to speed up the process of combat, strengthen reaction ability. Which mean that the perception of combat spatial will be higher, the decision making process will be shorter and more effective and the battle management will be more flexible and prominent. Operational cost will be reduced and the effectiveness will be improved and these are what we ultimately want.

B. Architecture of the command and control system in the Joint operations

Usually there are three level of command and control organization established in the joint operations [2], shown as Figure 1. 


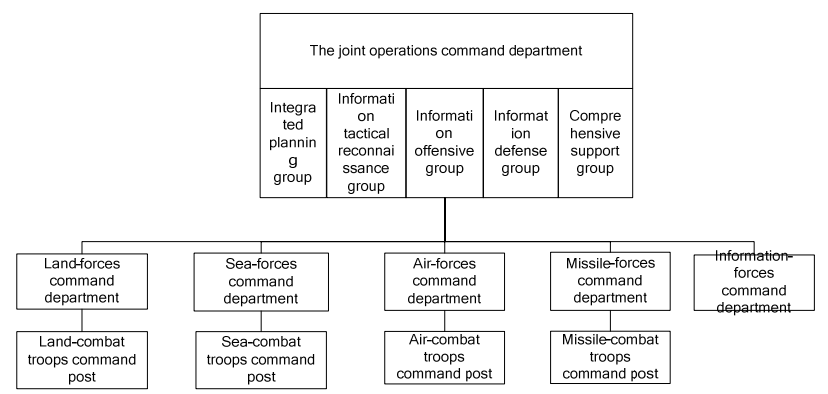

Figure 1. Three level architecture of command and control systems in the joint operations

The main duties of the joint operations command department are intelligence reconnaissance, information collection, making the joint operations determination, grasping the relevant situations of the battlefield, making joint operation plans, organizing and coordinating landforces, sea-forces, air-forces and missile-forces in combat formation, guiding reconnaissance operations, information offensive operations, information defense operations, and organizing and coordinating those kinds of combat operations. The duties of military branches command departments are similar to the details above. The difference is that the joint operations command department is responsible for directing operations within the scope of the entire battlefield, focusing on working with the overall planning and coordination. The military branches command department emphasize particularly on the detail mission for their own troops guided by the joint operation plans.

Joint operations command department is constitutive of integrated planning group, information tactical reconnaissance group, information offensive group, information defense group and comprehensive support group.

The main responsibility of integrated planning group is to coordinate unified operations of other combat groups to make sure the consistent of information offensive operations, information defense operations and information support operations.

Information tactical reconnaissance group is constituted by the staff officers who are familiar with all military branches electronic warfare reconnaissance and computer network reconnaissance. The main responsibility is to make reconnaissance operation plans, and to command and coordinate all military branches reconnaissance operations.

Information offensive group is constituted by the staff officers who are familiar with the operations of all military branches. The main responsibility is to make information offensive plans, information deception plans, and conduct all military branches information offensive operations.

Information defense group is constituted by the staff officers who are familiar with all military branches communication and electronic confrontation operations. The main responsibility is to make the information defense plans of electronic anti-interference, electronic camouflage, antiweapons of precision-guided, to coordinate and conduct the defense operations of all forces in the combat formation.
The architecture of the joint operations command department should be beneficial to achieve a high level of centralized and unified command, but also easy to organize and coordinate all military branches combat operations effectively. The architecture we proposed is based on the idea of joint operations integration. It is a higher level construction mode, in order to achieve the harmonization of the each operation group, good for the integration of the joint operations command.

\section{Construction of effectiveness evaluation indicators}

Base on the above analysis, according to the new characteristics of command and control system in the joint operations. We build three levels evaluation indicators, corresponding to the four levels of C4ISR system evaluation indicators[3], dimensional parameter (DP), measures of performance (MOP), measures of effectiveness (MOE), and measures of force effectiveness (MOFE), shown as Figure2. The top level is system effectiveness indicators, reflecting the effectiveness of command and control system in entire battlefield environments, which is constructed by three degree of command and control subsystems acted as an integrated system. The effectiveness indicators include the ability of posture sharing, the complete degree of combat mission, damage rate, accidental injury rate and etc. The second level is the system capacity indicators, reflecting the system ability of completing certain task, such as ability of information processing, ability of command and control and etc. The third level is the system functionality and performance indicators, reflecting the functionality and performance abilities of each logic module in the system.

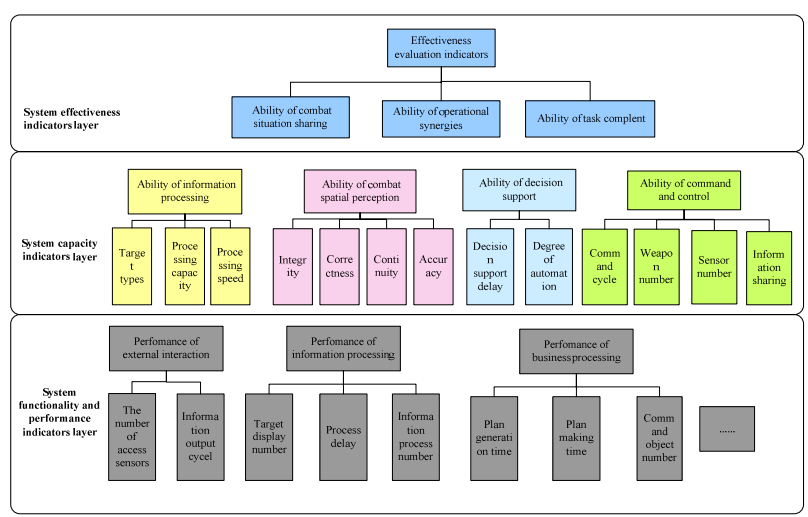

Figure 2. Effectiveness evaluation indicators of command and control system

Compared to the traditional command and control system, the system in joint operations we cared about has different concerns. It more concerns about integrated system constructed by the three degree of command and control subsystems, not a function or performance indicator of a command and control subsystem. We should evaluate it from an overall perspective. Take the ability of situation awareness for example, we concern about the completeness and accuracy of the entire integrated intelligence, no longer the intelligence of certain military branches. We concern 
about the ability of operational synergies, the effectiveness created by the organization and coordination operations in combat forces, no longer operational effectiveness of certain combat forces.

\section{EFFECTIVENESS EVALUATION OF COMMAND AND CONTROL SYSTEM}

\section{A. Comparisons of evaluation methods}

Effectiveness evaluation of command and control system is a very complicated problem. Because of the different position and different point of view, observers may have different understandings to the problems of system evaluation. There are lots of researches on the methods of system evaluation at home and abroad. This paper analyzes some of the major evaluation methods. Their main characteristics and representative methods[4] are listed in TABLE 1.

TABLE I. EFFECTIVENESS EVALUATION METHODS COMPARISON

\begin{tabular}{|c|c|c|}
\hline $\begin{array}{l}\text { Evaluation } \\
\text { methods } \\
\end{array}$ & $\begin{array}{l}\text { Representative } \\
\text { methods }\end{array}$ & Main characteristics \\
\hline $\begin{array}{l}\text { Analytical } \\
\text { methods }\end{array}$ & Queuing theory & $\begin{array}{l}\text { Effectiveness equation is } \\
\text { established based on mathematical } \\
\text { techniques. The advantage is the } \\
\text { formula is transparent and easy to } \\
\text { calculate, the disadvantage is } \\
\text { difficult to establish mathematical } \\
\text { models for complex joint } \\
\text { operational indicators. }\end{array}$ \\
\hline \multirow{4}{*}{$\begin{array}{l}\text { Comprehensive } \\
\text { evaluation } \\
\text { methods }\end{array}$} & $\begin{array}{l}\text { Hierarchy } \\
\text { analytic method }\end{array}$ & \multirow{4}{*}{$\begin{array}{l}\text { Using a combination of qualitative } \\
\text { and quantitative methods to break } \\
\text { down complex problems to each } \\
\text { component, group the elements by } \\
\text { hierarchical structure formation } \\
\text { according to their relationships, } \\
\text { and get the total order at last. The } \\
\text { advantage is available on a variety } \\
\text { of command and control system } \\
\text { solutions and task analysis, the } \\
\text { disadvantage is difficult to } \\
\text { describe the nonlinear relationship. }\end{array}$} \\
\hline & $\begin{array}{l}\text { Fuzzy integrated } \\
\text { evaluation } \\
\text { method }\end{array}$ & \\
\hline & $\begin{array}{l}\text { Multi-attribute } \\
\text { utility function } \\
\text { method }\end{array}$ & \\
\hline & $\begin{array}{l}\text { Grey Relation } \\
\text { Evaluation } \\
\text { method }\end{array}$ & \\
\hline \multirow[t]{4}{*}{$\begin{array}{l}\text { Simulation } \\
\text { Methods }\end{array}$} & $\begin{array}{l}\text { Computer } \\
\text { simulation }\end{array}$ & \multirow{4}{*}{$\begin{array}{l}\text { Using simulation modeling } \\
\text { techniques to establish simulation } \\
\text { models and experiment. Getting } \\
\text { effectiveness evaluation values by } \\
\text { processing mass of experiment } \\
\text { data. }\end{array}$} \\
\hline & $\begin{array}{l}\text { Prototyping } \\
\text { simulation }\end{array}$ & \\
\hline & $\begin{array}{l}\text { Test-bed } \\
\text { simulation }\end{array}$ & \\
\hline & $\begin{array}{l}\text { Combat- } \\
\text { simulation-based } \\
\text { method }\end{array}$ & \\
\hline \multirow{3}{*}{$\begin{array}{l}\text { System model } \\
\text { methods }\end{array}$} & Petri-Net & \multirow{3}{*}{$\begin{array}{l}\text { Theoretical basis is rigorous, but } \\
\text { the existing model in command } \\
\text { and control system lacks of } \\
\text { "decision", communication and } \\
\text { some other modeling. }\end{array}$} \\
\hline & $\begin{array}{l}\text { Lanchester } \\
\text { equation }\end{array}$ & \\
\hline & $\begin{array}{l}\text { Influence } \\
\text { Diagrams }\end{array}$ & \\
\hline
\end{tabular}

In essence, those methods mainly evaluate the static properties and dynamic properties of the system. Static properties describe their own performance and functionality indicators of the system (such as ability of information processing, ability of command and control, ability of decision support, etc.), it has nothing to do with the battlefield environment. Dynamic properties describe the operational performance in the battlefield environment which is also called system effectiveness, and the relationship between system and operational outcomes which is called system operational effectiveness [5].

From the above analysis, compared to the traditional command and control system, the system in joint operations have some new characteristics, like more operational resources, more kinds of combat operations, requiring high reaction, etc. So effectiveness evaluation of command and control system in joint operations will be focused on whether the system could achieve the aim goal successfully, the combat formation allocation is optimized, the joint operational plan is reasonable, organization and coordination is flexible and efficient, and the overall effectiveness is improved and so on. For this consideration, we decide to use the combat-simulation-based method for the evaluation. Using system simulation modeling techniques to construct models to represent the command and control system. Do research and experiment by simulating the process of largescale campaign-level combat in environmental conditions. Compared to the other methods, combat-simulation-based method can fully consider the uncertainties of the combat operations, simulate the process of information flow and operational dynamic evolution, describe the complex interactions between systems fully, and express the organization and coordination operations in red and blue systems effectively. It can provide data to support effectiveness evaluation for command and control system in joint operations, to analyze the problems and deficiencies exposed during the combat simulation and the most important thing is to improve and correct it.

\section{B. Implementation steps of evaluation}

This paper constructs the experiment framework based on combat -simulation-based method. The design idea is modeling red and blue confrontation systems models. The most important thing is to construct three degree of command and control system models. We assign offensive and defensive combat missions for both sides, and run the simulation of the confrontation process to get the operational result of command and control system completed. In comprehensive, on the basis of a large number of different scenarios, we make different joint operational plans, construct different combat forces formation, and adjust command and coordination orders. Through the interaction between command and control system and other systems, we get and evaluate a large number of simulation results to analyze the influence of different factors impacting on command and control system effectiveness, the framework is designed as Figure 3. 


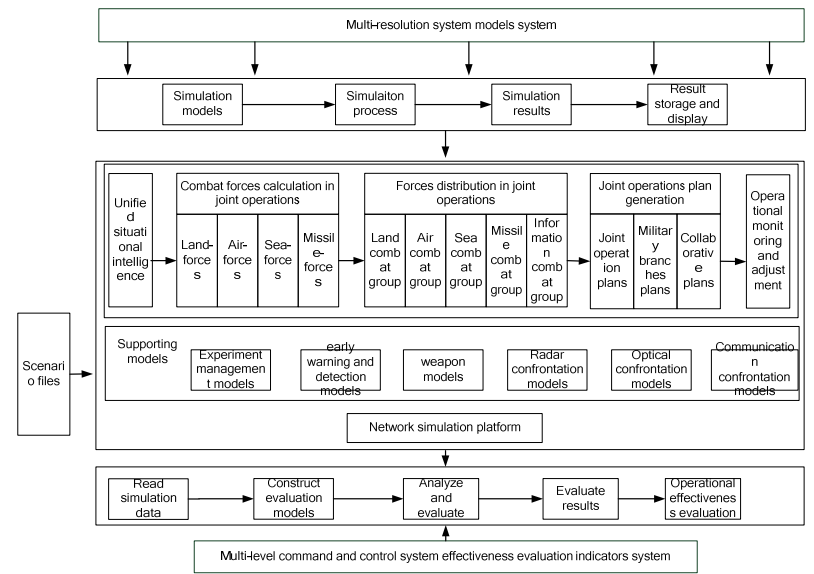

Figure 3. Combat Simulation experiment Framework of command and control system in joint operations

Combat-simulation-based experiment framework contains "two systems", "multi-level command and control system effectiveness evaluation indicators system” and "multi-resolution system models system". The complexity and diversity of command and control system in joint operations determines the effectiveness evaluation indicator should be multilayered. Each degree of command and control systems plays a different role in the process of the joint operations, and their evaluation focus is different. We need to perform the task completing effectiveness of each command and control system from different sides and different level, and then constitute those indicators to an organic whole, reflecting the entire command and control system effectiveness indicators. In order to get those multilevel effectiveness indicators, we must establish objects models, activities models and process models related to the joint combat system constructed with different resolution and described in different abstraction degree. Such as early warning and detection models, weapon models, confrontation combat models, environment models and etc. And we have to choose the match models according to the nature of the problem. If we concern about the macroeconomic performance of the joint operation system, then choose the low-resolution models to save system resources and reduce computation. If we concern about a low-level evaluation indicators, then choose the highresolution models. So we have to construct a multi-resolution model library to perform the complexity of the joint operations combat system effectiveness evaluation.

The specific steps of evaluation experiment are listed as follows:

1) First step is to determine the evaluation plan and design the simulation environment according to the key evaluation indicators.

2) Second step is to propose the scenario file, and convert it to simulation script file.

3) Third step is to start the simulation.
4) Forth step is data collection while the simulation is running.

5) After the end of the simulation, reading the data to evaluate and analysis the comprehensive performance indicators of the system.

6) Base on the evaluation results of the analysis, adjusting operational plans and combat formation, then do again from step3) to re-start the simulation evaluation.

7) Comparatively analyze, organize and display those simulation results, shown as Figure 4.

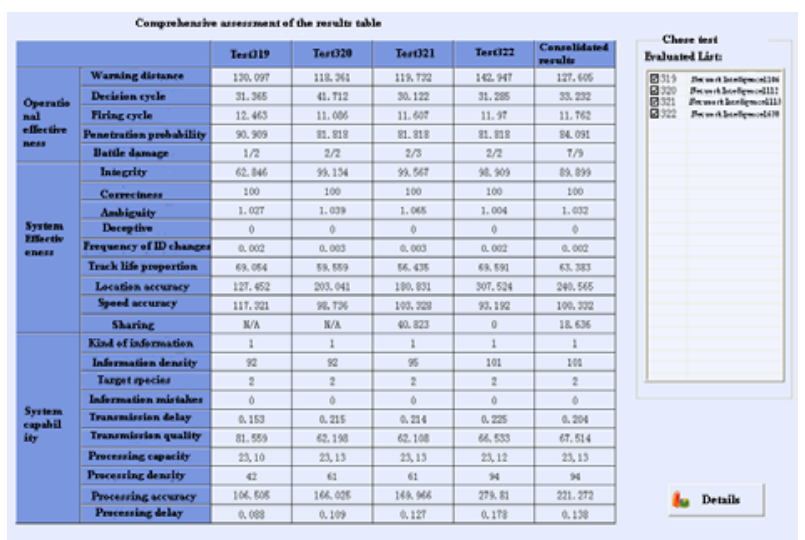

Figure 4. Comparison of simulation evaluation results

\section{CONCLUSION}

The effectiveness evaluation of command and control system in the joint operations is a complicated problem. This paper constructs the effectiveness evaluation indicators hierarchy based on the analysis of the architecture and characteristics of command and control system in the joint operations. Using the combat-simulation-based method, we design and implement the experiment framework to provide a technical support for evaluating the effectiveness of command and control system in the joint operations scientifically.

\section{REFERENCES}

[1] Li De-yi, Zeng Xhan-pin. “Automatic command in development”. Beijing: People’s liberation army Press,2004.

[2] Zhang Pei-gao. “Joint battle command tutorial”. Beijing:Military science Press,2012.

[3] Mao Shao-jie,Ju Zhen-qi,Li Yu-pin and Li Dan. "C ${ }^{4} I S R$ system simulation technology”. Beijing:Military science Press,2011.

[4] Chen Jian-ning. "Network-centric warfare command and control system and effectiveness evaluation". Doctoral Dissertation. School of mechatronics engineering and automation national university of defense technology,2007.

[5] Tang hong, Chen shao-qing. "Effectiveness evaluation of command and control system,” Journal of System Simulation, VOL.13, 2001,pp. 392-29. 